SCOTTÁ, B.A. et al. Influência dos minerais quelatados e inorgânicos no metabolismo, desempenho, qualidade da carcaça e da carne de frangos de corte. PUBVET, Londrina, V. 8, N. 9, Ed. 258, Art. 1710, Maio, 2014.

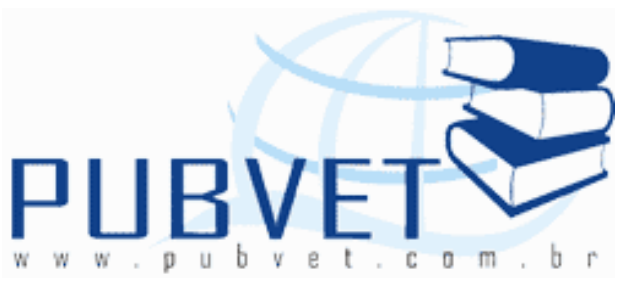

PUBVET, Publicações em Medicina Veterinária e Zootecnia.

\title{
Influência dos minerais quelatados e inorgânicos no metabolismo, desempenho, qualidade da carcaça e da carne de frangos de corte
}

\section{Bruno Andreatta Scottá ${ }^{1}$, Rodolfo Alves Vieira ${ }^{1}$, Ana Paula Cardoso Gomide ${ }^{1}$,} Priscila Furtado Campos ${ }^{1}$, Carlota Coelho Barroca ${ }^{1}$, Andressa da Silva Formigoni $^{2}$

${ }^{1}$ Doutorando (a) do Programa de Pós-Graduação em Zootecnia da Universidade Federal de Viçosa - UFV.

${ }^{2}$ Doutoranda do Programa de Pós-Graduação em Zootecnia da Universidade Federal de Minas Gerais - UFMG.

\section{Resumo}

Esta revisão teve como objetivo mostrar as principais diferenças no metabolismo e na biodisponibilidade dos minerais quelatados e inorgânicos para frangos de corte, e a influencia destes no desempenho, nas características de carcaça e na qualidade da carne. Os minerais quelatados apresentam alta biodisponibilidade e são mais prontamente absorvidos pelos animais que os minerais inorgânicos, com isso uma menor quantidade de minerais seriam excretados para o ambiente, alguns desses com alto poder poluente, tanto para o solo quanto para as águas. Os minerais quelatados também podem afetar de forma benéfica o desempenho dos frangos, sem afetar as características de carcaça e a qualidade da carne.

Palavras-chave: biodisponibilidade, mineral quelatado, nutrição animal 
SCOTTÁ, B.A. et al. Influência dos minerais quelatados e inorgânicos no metabolismo, desempenho, qualidade da carcaça e da carne de frangos de corte. PUBVET, Londrina, V. 8, N. 9, Ed. 258, Art. 1710, Maio, 2014.

\title{
Influence of organic and inorganic mineral in the metabolism, performance, carcass quality and meat of broilers
}

\begin{abstract}
This review aimed to show the main differences in the metabolism and bioavailability of inorganic and organic minerals for broilers, and these influences on performance, carcass characteristics and meat quality. The organic minerals present high bioavailability and are more readily absorbed by animals that inorganic minerals, thus less amounts of minerals to be excreted in the environment, some of these with high polluting power, both for soil and for the water. Organic minerals can also beneficially affect the performance of broilers without affecting carcass characteristics and meat quality.
\end{abstract}

Keywords: bioavailability, chelated minerals, animal nutrition

\section{1 - Introdução}

Minerais, tais como cobre, ferro, manganês, zinco e selênio são essenciais para o crescimento de frangos e estão envolvidos em muitos processos fisiológicos. Participam em quase todas as vias metabólicas do organismo animal, tendo importantes funções fisiológicas como na reprodução, no crescimento, no sistema imunológico e no metabolismo energético (Dieck et al., 2003) . Normalmente esses minerais são suplementados na forma de sais inorgânicos, como os sulfatos, óxidos e carbonatos, para garantir um desenvolvimento saudável e melhora da produtividade dos animais.

As exigências de minerais traços para frangos de corte se referem aos mesmos níveis recomendados pelo NRC (1994), sendo algumas baseadas em dados de 1950, com isso, nutricionistas frequentemente utilizam níveis mais elevados de minerais, grande parte das vezes baseado em seu próprio conhecimento prático (Leeson, 2008).

Na prática, o aumento da margem de segurança na suplementação de microminerais resulta em alto nível de excreção mineral. Obviamente, isso 
SCOTTÁ, B.A. et al. Influência dos minerais quelatados e inorgânicos no metabolismo, desempenho, qualidade da carcaça e da carne de frangos de corte. PUBVET, Londrina, V. 8, N. 9, Ed. 258, Art. 1710, Maio, 2014.

não é apenas um desperdício, mas também causa impactos ao meio ambiente. A preocupação com o acúmulo de minerais no ambiente, especialmente $\mathrm{Zn}$ e $\mathrm{Cu}$, leva ao questionamento sobre as práticas de alimentação atual, no sentido de como reduzir os níveis de suplementação mineral nas dietas sem comprometer a nutrição dos animais e a qualidade nutricional dos produtos gerados.

O uso de minerais quelatados e de selênio levedura tem sido sugerido como solução para este problema, com base na hipótese de que o mineral complexado na forma de quelatos e a selênio levedura têm maior biodisponibilidade quando comparados às fontes inorgânicas. Isto implica que os minerais quelatados e o selênio levedura podem ser adicionados em concentração menor na dieta em relação aos minerais inorgânicos, sem qualquer efeito negativo sobre o desempenho produtivo e reduzindo a excreção de minerais.

O uso de minerais quelatados e selênio levedura também podem melhorar a qualidade da carcaça, pois pode afetar a quantidade de gordura abdominal, o que melhora o aceite da carne de frango pelo consumidor. A qualidade da carne também pode ser afetada com algumas melhorias demonstradas na maciez, oxidação lipídica o que pode levar a um aumento do tempo de prateleira da carne, uma menor perda de água, entre outras.

Esta revisão teve como objetivo mostrar as principais diferenças no metabolismo e biodisponibilidade dos minerais orgânicos e inorgânicos para aves, e a influencia destes no desempenho, qualidade da carcaça e da carne de frangos.

\section{2 - Função dos Microminerais}

\section{1 - Cobre (Cu)}

O Cu é necessário para a respiração celular, a formação óssea, função cardíaca, desenvolvimento de tecido conjuntivo, mielinização do sistema nervoso central, queratinização e pigmentação de tecidos. Ele é componente 
SCOTTÁ, B.A. et al. Influência dos minerais quelatados e inorgânicos no metabolismo, desempenho, qualidade da carcaça e da carne de frangos de corte. PUBVET, Londrina, V. 8, N. 9, Ed. 258, Art. 1710, Maio, 2014.

essencial de muitas metalo-enzimas incluindo a citocromo-oxidadese, a superóxido dismutase, a dopamina beta hidroxilase-tironase.

Junto com o ferro o Cu é necessário para síntese de hemoglobina. Não há Cu na hemoglobina, mas esse elemento atua como catalisador na formação de hemoglobina. A ceruplasmina ferroxidasa que é sintetizada no fígado e contem $\mathrm{Cu}$, permite a união do $\mathrm{Fe}$ com a proteína transferrina para o transporte de Fe.

Uma série de patologias estão associadas á sua deficiência, incluindo anemia, diarréia, redução da pigmentação das penas e da atividade de uma série de enzimas, falhas reprodutivas, desordens nervosas e cardiovasculares, fragilidade óssea e espessura da cartilagem.

Nos animais monogástricos a absorção ocorre principalmente na parte superior do intestino delgado, isto porque o $\mathrm{pH}$ ainda é um pouco mais ácido. $\mathrm{A}$ absorção do mineral é aumentada em situações de deficiência do próprio, já o excesso de minerais como cálcio, ferro, zinco e cádmio podem reduzir a absorção do cobre.

\section{2 - Zinco (Zn)}

O Zn é componente de metaloenzimas, incluindo sintetases e transferases de DNA e RNA, de enzimas digestivas e está associado com a insulina. Tem papel importante no metabolismo das proteínas, dos carboidratos e dos lipídios.

Quantidades substanciais de $\mathrm{Zn}$ estabilizam as estruturas do RNA, do DNA e dos ribossomos. Atualmente são conhecidas mais de 200 proteínas contendo Zn. O Zn é cofator da anidrase carbônica que atua na calcificação dos ossos e formação da casca do ovo, e essencial para a integridade do sistema imune. Ele desempenha importante papel na secreção de hormônios, produção de queratina e síntese de colágeno e ácidos nucléicos na pele. A firmeza da pele está altamente correlacionada ao conteúdo de colágeno e sua presença garante a manutenção da qualidade da pele. 
SCOTTÁ, B.A. et al. Influência dos minerais quelatados e inorgânicos no metabolismo, desempenho, qualidade da carcaça e da carne de frangos de corte. PUBVET, Londrina, V. 8, N. 9, Ed. 258, Art. 1710, Maio, 2014.

A maior absorção ocorre no duodeno, o primeiro passo para a absorção de $\mathrm{Zn}$ envolve a sua transferência do lúmen do intestino para as células da mucosa. O transporte através da membrana é um processo mediado por carreadores e provavelmente envolve a interação com formas quelatadas de $\mathrm{Zn}$. Um grande número de quelatos de reduzido peso molecular, incluindo citrato, picolinato, ácido etilenodiaminotetracético (EDTA) e aminoácidos como histidina e ácido glutâmico atravessam a parede celular e aumentam adsorção de $\mathrm{Zn}$. Dentro das células da mucosa a transferência de Zn é mediada por uma proteína do fígado (metalotioneina), esta proteína controla a homeostase do Zn no corpo. Alguns componentes da dieta como fitato, cálcio, fibra, fósforo, cobre, cádmio, e cromo podem reduzir a absorção do $\mathrm{Zn}$.

A deficiência de $Z n$ é conhecida como paraqueratose. Também pode afetar as secreções pancreáticas e de outros sistemas enzimáticas. Concentrações de Ca e P influenciam o metabolismo e as exigências de Zn. A exigência de $\mathrm{Zn}$ aumenta quando a dieta apresenta níveis reduzidos de Ca e diminui quando os níveis de $P$ da dieta são baixos.

\section{3 - Manganês (Mn)}

O Mn é componente de enzimas (quinases, hidrolases, trasferases e descarboxilases) envolvidas no metabolismo dos carboidratos, dos lipídios e das proteínas. É componente dos mucopolissacarídeos na matriz orgânica dos ossos. O Mn participa no desenvolvimento de cartilagens, e também propicia uma resistência contra a ação de agentes oxidantes e consequente formação de radicais livres nas células. Possui ainda função imune associando-se a macrófagos e neutrófilos.

A absorção ocorre em toda a extensão do intestino delgado. Em todas as espécies a absorção é relativamente baixa, em torno de $4 \%$, e é influenciada pela presença de minerais especialmente, $\mathrm{Ca}, \mathrm{P}$ e Fe.

As principais manifestações de deficiência são: redução de crescimento e anormalidades ósseas. 
SCOTTÁ, B.A. et al. Influência dos minerais quelatados e inorgânicos no metabolismo, desempenho, qualidade da carcaça e da carne de frangos de corte. PUBVET, Londrina, V. 8, N. 9, Ed. 258, Art. 1710, Maio, 2014.

\section{4 - Selênio (Se)}

Componente da enzima glutationa peroxidase, que detoxifica peróxidos de lipídios, protegendo as membranas celulares. Interage com a vitamina E na prevenção de danos causados por peróxidos e outros compostos reativos formados durante os processos metabólicos normais das membranas celulares. A glutationa peroxidase ocorre principalmente no citosol e reduz os peróxidos antes deles atacarem as membranas celulares, enquanto a vitamina E atua dentro da membrana celular, como uma segunda barreira de proteção.

$O$ principal constituinte de selênio no plasma é a selenoproteina $P$, uma singular molécula com ate dez resíduos de selênio-cisteina (Se-Cis) incorporados nos peptídeos como base. As principais formas de selênio inorgânico são os sais de $\mathrm{Se}$, ou seja, selenato $\left(\mathrm{SeO}_{4}{ }^{-2}\right)$ e selenito $\left(\mathrm{SeO}_{3}{ }^{-2}\right)$. Por sua vez, a forma orgânica mais comum do Se na planta é a selenometionina (SeMet) ou selenocistina (SeCis), ou seja, uma forma análoga dos aminoácidos sulfurados.

O modelo cinético do metabolismo do Se como SeMet difere do metabolismo do Se como selenito, de forma que a selenometionina pode apresentar uma absorção de $98 \%$, do absorvido, $43 \%$ chega aos tecidos periféricos muito lentamente, o que não é conseguido pelo Se na forma de selenito.

\section{5 - Ferro (Fe)}

Aproximadamente $60 \%$ do ferro do corpo estão presentes como hemoglobina, um complexo da heme protoporfirina e globina. Como oxihemoglobina leva oxigênio do pulmão para os tecidos pelo sangue arterial, e devolve levando gás carbônico como carboxihemoglobina pela circulação venosa. A mioglobina é a mais simples e menos abundante ferro porfirina presente no músculo, sendo sua afinidade mais alta para oxigênio, completa a transferência do oxigênio da hemoglobina na célula. Por muitos anos, foi 
SCOTTÁ, B.A. et al. Influência dos minerais quelatados e inorgânicos no metabolismo, desempenho, qualidade da carcaça e da carne de frangos de corte. PUBVET, Londrina, V. 8, N. 9, Ed. 258, Art. 1710, Maio, 2014.

focalizado o interesse nutricional do ferro em seu papel na hemoglobina, através da formação e transporte de oxigênio. Um conceito mais amplo do significado fisiológico do ferro se desenvolveu quando foi observada a presença de ferro nas enzimas do citocromo e o papel destas enzimas nos mecanismos oxidativos de todas as células.

A forma física ou química do ferro também influencia na sua absorção. As fontes de origem animal são mais disponíveis do que as fontes vegetais. Isto é devido à grande proporção de ferro heme nas fontes animais. O ferro heme é absorvido como um complexo porfirina intacto enquanto que o ferro não heme tem de ser removido da proteína ligada ao complexo para absorção.

\section{3 - Minerais Quelatados}

Os microminerais orgânicos ou quelatados são componentes naturais dos organismos animais e vegetais. Circulam na forma complexada e não como íons inorgânicos livres. Eles apresentam baixo peso molecular e a capacidade oxidativa ou "ligante" depende do tamanho da molécula e da presença de radicais carboxílicos. As principais são os ácidos aminado, ascórbico, cítrico, glucônico e etilenodiaminotetracético (EDTA). Normalmente, um mineral pode fazer a ligação com uma, duas ou várias dessas moléculas para formar um "composto mineral organicamente ligado" ou quelato, podendo assim ser vendido como fonte de mineral.

Existem diferentes formas de minerais quelatados e complexados disponíveis no mercado. De acordo com a Association of American Feed Control Officials (AAFCO, 1999), existem cinco categorias de microminerais quelatados:

Complexo Metal Aminoácido Específico - resultante da complexação de um sal de metal solúvel com um aminoácido específico, geralmente referese a uma molécula de aminoácido ligada a um íon metal. Essa ligação é mais consistente que quelatos, proteinatos e polissacarídeos, onde a maioria desses produtos é composta por microminerais aleatoriamente ligados a dipeptídeos, 
SCOTTÁ, B.A. et al. Influência dos minerais quelatados e inorgânicos no metabolismo, desempenho, qualidade da carcaça e da carne de frangos de corte. PUBVET, Londrina, V. 8, N. 9, Ed. 258, Art. 1710, Maio, 2014.

tripeptídeos ou fragmentos de proteínas. O complexo metal aminoácido específico é bem definido e muito consistente em sua produção. Exemplos: Zinco-Metionina, Manganês-Metionina, Cobre-Lisina e Ferro-Metionina;

Complexo Metal Aminoácido - muito semelhante ao complexo metal aminoácido específico, é resultante da complexação de um sal de metal com uma mistura de aminoácidos livres. A única diferença entre as duas categorias é que o aminoácido não é especificado.

Quelato Metal Aminoácido - resultante da reação de um íon metálico de um sal solúvel com aminoácidos em uma reação molar de um mol de metal para um, dois ou três (preferencialmente dois) mols de aminoácidos, formando uma ligação covalente coordenada. Por definição, quelatos de metais são como os proteinatos, a diferença é que os quelatos devem ter um peso molecular máximo pré-determinado de 800 Daltons. Quando o tamanho do ligante aumenta, diminui a força da ligação entre as moléculas e pode reduzir a absorção.

Metal Proteinato - resultante da quelatação de um sal solúvel com aminoácidos e/ou proteínas parcialmente hidrolisadas. O produto final pode conter somente aminoácidos, dipeptídeos, tripeptídeos ou outros derivados de proteína. Geralmente, a mistura resultante possui uma ligação muito fraca, muitas vezes incapaz de resistir ao ambiente do trato gastrintestinal. Esses produtos são menos consistentes por definição e variam na produção e resultados de pesquisas.

Metal Polissacarídeo - resultante da complexação de um sal solúvel com um polissacarídeo. Este produto é uma matriz de mineral orgânico, sem ligações químicas entre o metal e o polissacarídeo. A matriz de polissacarídeo somente envolve o micromineral, promovendo alguma proteção física contra a degradação intestinal.

Alternativamente, os minerais orgânicos podem ser sintetizados pelo processo biossintético a partir do enriquecimento de uma cultura de levedura (Saccharomyces cerevisiae) com selênio inorgânico. A semelhança química entre o selênio e o enxofre propicia a incorporação do selênio ao invés do 
SCOTTÁ, B.A. et al. Influência dos minerais quelatados e inorgânicos no metabolismo, desempenho, qualidade da carcaça e da carne de frangos de corte. PUBVET, Londrina, V. 8, N. 9, Ed. 258, Art. 1710, Maio, 2014.

enxofre na metionina ou cisteína pela levedura durante a formação dos compostos celulares (Rutz e Murphy, 2009).

\section{4 - Metabolismo dos Minerais Quelatados X Inorgânicos}

Interações negativas entre íons metálicos e fatores dietéticos sempre foram uma preocupação. Dentre estes fatores estão o ácido fítico, que complexa elementos traço, tais como o zinco, o cobre, o ferro, e o manganês, resultando em redução na absorção destes elementos chave. O antagonismo também ocorre entre os elementos cujas estruturas eletrônicas e estados são similares. Por exemplo, o ferro, o manganês e o cobalto são mutuamente antagonistas com respeito à absorção intestinal. Isto ocorre provavelmente devido a semelhança dos mecanismos de absorção. Entretanto, algumas das maiores interações adversas ocorrem em íons metálicos sujeitos a reações de hidroxi-polimerização.

Os metais ingeridos podem ser subdivididos em duas categorias gerais: aqueles solúveis em uma ampla variação de $\mathrm{pH}$ no trato gastrintestinal, ex. sódio, cálcio e magnésio e aqueles susceptíveis a reação de hidroxipolimerização, como o alumínio, o manganês, o zinco, o cobre e o ferro. Eles são prontamente solúveis em ácido (ex. no estômago de monogástricos), mas em condições de alcalinização no intestino delgado, as moléculas de água as quais eles estão ligados perdem rapidamente seus prótons para formar compostos hidroxi-metálicos. Conforme a solução acidifica e se aproxima do $\mathrm{pH}$ neutro, outros prótons são liberados pelas moléculas de água coordenadas ao redor do metal numa tentativa de manter o equilíbrio. Isto pode levar a uma ampla polimerização dos hidróxi-metais e, por fim, precipitação, tornando o metal não disponível para a absorção.

Estes não são os únicos entraves na absorção dos minerais encontrados no trato digestivo. Durante a digestão, os nutrientes no lúmen (incluindo os minerais que não precipitaram) são direcionados para a vilosidade do intestino delgado, mas primeiro deparam-se com uma camada de água com 
SCOTTÁ, B.A. et al. Influência dos minerais quelatados e inorgânicos no metabolismo, desempenho, qualidade da carcaça e da carne de frangos de corte. PUBVET, Londrina, V. 8, N. 9, Ed. 258, Art. 1710, Maio, 2014.

características não homogêneas. Esta mede em torno de $600 \mu \mathrm{m}$ de espessura. Logo abaixo, uma nova camada de muco, medindo 50-100 $\mu \mathrm{m}$ de espessura, antes de chegar à membrana do enterócito, onde ocorre a absorção propriamente dita e a membrana mede nanômetros e não micrometros. Portanto, é evidente que antes que um íon metálico possa ser absorvido, ele não deve estar envolvido com a hidroxi-polemerização, atravessar as barreiras e chegar ao enterócito.

Durante muitos anos, várias hipóteses foram desenvolvidas para explicar o mecanismo de absorção de minerais quelatados na parede intestinal. A incorporação do mineral junto aos quelatos (ex. aminoácido ligado ao mineral) aumentaria a sua absorção, pois o mineral seria absorvido como de "carona". Este tipo de modelo é convincente com respeito ao tamanho ótimo do ligante para assegurar transporte intacto do mineral, mas ele geralmente ignora as interações e reações que ocorrem no microclima intestinal antes da absorção. Este microclima ali existente apresenta um efeito extremamente importante na absorção de nutrientes no nível do enterócito em si.

Miles \& Henry (2000) estabeleceram uma série de hipóteses algumas validas, outras não e levantaram uma série de questionamentos sobre minerais quelatados que são citadas a seguir:

A estrutura em anel protege o mineral de reações químicas indesejáveis no trato gastrintestinal; quelatos passam facilmente através da parede intestinal para a corrente sanguínea; a absorção passiva é aumentada ao reduzir a interação entre minerais e outros nutrientes; o mineral é oferecido ao animal da mesma forma que é encontrado no corpo; os quelatos são absorvidos através de vias diferentes da dos minerais inorgânicos; cada mineral no quelato facilita a absorção de outros minerais no quelato; os quelatos carreiam uma carga negativa, de forma que são absorvidos e metabolizados mais eficientemente; a quelatação aumenta a solubilidade e o movimento através membranas celulares; a quelatação aumenta a absorção passiva ao aumentar a solubilidade do mineral na fase aquosa e lipídica; a 
SCOTTÁ, B.A. et al. Influência dos minerais quelatados e inorgânicos no metabolismo, desempenho, qualidade da carcaça e da carne de frangos de corte. PUBVET, Londrina, V. 8, N. 9, Ed. 258, Art. 1710, Maio, 2014.

quelatação aumenta a estabilidade a um baixo $\mathrm{pH}$; os quelatos são absorvidos pelo mecanismo de transporte dos aminoácidos.

\section{5 - Biodisponibilidade e Desempenho}

São inúmeros os trabalhos que evidenciam diferenças na biodisponibilidade entre as fontes de minerais quelatados em relação às fontes inorgânicas na nutrição de aves e também no desempenho dos animais.

Banks et al. (2004) trabalhando com diferentes fontes de Cu (Citrato de $\mathrm{Cu}$, Sulfato de $\mathrm{Cu}$, Cloreto de $\mathrm{Cu}$ e $\mathrm{Cu}$-lisina), não observarem diferença nas variáveis de desempenho, entretanto os frangos alimentados com 250 ppm de citrato de $\mathrm{Cu}$ ou sulfato de $\mathrm{Cu}$ apresentaram menor retenção de $\mathrm{P}$ aparente na tíbia e a suplementação com 250 ppm cloreto de $\mathrm{Cu}$ ou Cu-lisina não resultaram numa redução da retenção de $P$ aparente, em comparação com os animais alimentados com baixo-P na dieta. A suplementação de 250 ppm sulfato de $\mathrm{Cu}$ resultou em melhoradas aparentes nas retenções de $\mathrm{Cu}$.

Chowdhury et al. (2004), ao fornecerem diferentes fontes (Sulfato de cobre e cobre-proteinato) e concentrações (200 e 400ppm) de Cu para frangos de corte observaram que a maior suplementação de $\mathrm{Cu}$ diminuiu os níveis plasmáticos de colesterol LDL-C e aumentou o HDL-C em frangos de corte e que isso foi mais evidente para o Cu-proteinato. A concentração dietética elevado de $\mathrm{Cu}$ aumenta o $\mathrm{Cu}$ no fígado, e este regula a biossíntese de colesterol hepático, reduzindo a concentração de glutationa reduzida (GSH), o que reduz a atividade da HMG-CoA redutase, a enzima chave da biossíntese do colesterol, diminuindo assim a biossíntese do colesterol.

Paik et al. (1999) avaliaram a utilizando de fontes orgânicas (Cu-Met) e inorgânicas $\left(\mathrm{CuSO}_{4}\right)$. Os autores observaram que pintinhos suplementados com quelato $\mathrm{Cu}$-metionina (125 ppm) tiveram maior ganho diário de peso em cinco semanas após o nascimento que os animais que receberam sulfato de cobre na ração. Observou-se também que o cobre proveniente do quelato $\mathrm{Cu}$ - 
SCOTTÁ, B.A. et al. Influência dos minerais quelatados e inorgânicos no metabolismo, desempenho, qualidade da carcaça e da carne de frangos de corte. PUBVET, Londrina, V. 8, N. 9, Ed. 258, Art. 1710, Maio, 2014.

Met foi melhor absorvido, obteve maior acúmulo no músculo do peito e menor acúmulo no fígado comparado à fonte inorgânica de sulfato de cobre.

Huang et al. (2009), estimaram a biodisponibilidade de três fontes de Zinco quelatados em relação ao sulfato de Zn através da concentração de metalodionina no pâncreas e concentração de Zn na tíbia. A fonte e a concentração de $\mathrm{Zn}$ não afetaram os parâmetros de desempenho dos animais e a fonte não afetou a concentração de Zn no osso e no pâncreas e na concentração de metalodionina, entretanto as concentrações foram maiores para as maiores suplementações de $\mathrm{Zn}$.

Ao et al. (2009) verificaram o efeito do fornecimento de fontes orgânicas e inorgânicas de $\mathrm{Zn}$ e Cu sobre a deposição tecidual. A concentração de Cu no fígado diminuiu com a adição de $\mathrm{Zn}$. O conteúdo de $\mathrm{Zn}$ na mucosa intestinal aumentou com o fornecimento de $\mathrm{Zn}$ quelatado e não houve efeito para $\mathrm{O}$ inorgânico. A concentração de $\mathrm{Cu}$ na mucosa intestinal aumentou com a suplementação tanto de $\mathrm{Zn}$ como de Cu na forma quelatada.

Ji et al. (2006) trabalhando com diferentes fontes de $\mathrm{Mn}$ verificaram que no íleo ocorre a maior absorção do mineral e que as fontes quelatadas apresentam absorção superior às inorgânicas e os minerais complexados com aminoácidos de forma mais fortes apresentaram melhor biodisponibilidade.

Tucker (2008) menciona que frangos recebendo dietas contendo manganês na forma orgânica apresentam melhor desempenho que aqueles recebendo este mineral na forma inorgânica. Níveis de 30 ppm Mn não foram suficientes para sustentar o ganho de peso corporal. Aves recebendo manganês orgânico apresentaram maiores ganhos de peso (comparativamente aos que receberam 30 ppm Mn orgânico, ou 30 ou 60 ppm de Mn inorgânico).

Payne \& Southern (2005) trabalhando com diferentes fontes de Se (orgânico e inorgânico) verificaram que o selênio levedura (forma orgânica) aumentou os níveis de Se na musculatura e no plasma do animal em relação ao selenito de sódio, entretanto não foi verificadas diferenças nas variáveis de desempenho e atividade da enzima glutationa peroxidase. 
SCOTTÁ, B.A. et al. Influência dos minerais quelatados e inorgânicos no metabolismo, desempenho, qualidade da carcaça e da carne de frangos de corte. PUBVET, Londrina, V. 8, N. 9, Ed. 258, Art. 1710, Maio, 2014.

Yoon et al. (2007) estudaram diferentes fontes e concentrações de Se e seu efeito no desempenho e na retenção do mineral. À medida que aumentou a concentração de Se houve um aumento na concentração de glutationa peroxidase no plasma, sendo que o Se levedura promoveu maior concentração da enzima em relação ao selenito de sódio, entretanto não foi verificado diferença nas variáveis de desempenho.

Ma et al. (2012) trabalhando com Fe-glicina e seu efeito no desempenho, deposição tecidual, excreção do mineral e atividade de enzimas antioxidantes no fígado (superoxido dismutase - SOD e catalase - CAT), verificou que o $\mathrm{Fe}$ glicina promoveu melhor desempenho, maior deposição tecidual de Fe e maior atividade das enzimas SOD e CAT em relação ao tratamento sem suplementação mineral e o Fe-glicina promoveu menor excreção de $\mathrm{Fe}$ em relação ao sulfato de Fe.

\section{6 - Qualidade da Carcaça}

A melhor qualidade de carcaça das aves esta intimamente relaciona com a menor deposição de gordura e um aumento na quantidade de tecido muscular (Rosa et al., 2000). A carne do peito das aves já apresenta baixo teor de gordura, no entanto a quantidade de gordura no tecido subcutâneo, na cavidade abdominal e nas sobrecoxas são maiores (Vieira, 1999). A quantidade de gordura nas carcaças de frangos de corte pode ser influenciada por diversos fatores como a genética do animal, o ambiente ao qual o animal esta inserido e também a nutrição (Kessler et al., 2000).

Os minerais podem estar diretamente relacionados com a qualidade da carcaça, pois muitos estão envolvidos nos processos metabólicos que influenciam na deposição de gordura e de tecido magro. O manganês é um exemplo interessante, pois ele esta envolvido na atividade de várias enzimas relacionadas com o metabolismo lipídico, entre estas enzimas podemos citar a lipase hormônio sensível (enzima dos adipócitos que clivam os ácidos graxos a partir do triacilglicerol intracelular), a lipoproteína lipase (enzima dos 
SCOTTÁ, B.A. et al. Influência dos minerais quelatados e inorgânicos no metabolismo, desempenho, qualidade da carcaça e da carne de frangos de corte. PUBVET, Londrina, V. 8, N. 9, Ed. 258, Art. 1710, Maio, 2014.

adipócitos que cliva os ácidos graxos a partir das lipoproteínas da circulação, permitindo que esses ácidos graxos entrem na célula e sejam oxidados ou esterificados em triacilglicerol) e a malato desidrogenase (enzima envolvida na síntese de NADPH que é um fator importante na síntese de lipídeos).

Fontes orgânicas e inorgânicas de minerais apresentam diferentes intensidades de ação, pois a biodisponibilidade das fontes orgânicas pode levar a uma maior concentração de minerais circulantes e assim potencializar suas funções fisiológicas. Lu et al. (2006) estudaram o efeito do nível de suplementação e da fonte de manganês sobre os parâmetros de carcaça de frangos de corte e não observaram efeito significativo entre a fonte orgânica ou inorgânica sobre os parâmetros de qualidade de carcaça, mas observaram efeito significativo do nível de manganês sobre a deposição de gordura abdominal, a maior suplementação de manganês levou a uma diminuição da deposição de gordura abdominal.

Outro mineral muito importante em relação aos parâmetros de qualidade da carcaça é o zinco, ele esta intimamente ligado á qualidade da pele, pois o zinco desempenha um papel importante na síntese de colágeno, o que a torna a pele mais resistente e menos propensa a rasgos, além disso o zinco também participa da síntese de ácidos nucleicos e de queratina na pele, participando intensamente na manutenção da qualidade da pele.

Rossi et al. (2007) estudaram a influencia da adição de zinco orgânico na dieta de frangos de corte sobre os parâmetros de qualidade de carcaça e de pele e não observaram diferença significativa para os parâmetros de qualidade de carcaça e de pele avaliados. Mas concluíram que mesmo não sendo observada uma diferença significativa para os parâmetros de qualidade da pele, houve uma clara tendência de melhoria das características da pele devido à adição de zinco orgânico nas dietas, com um aumento no numero de células epiteliais e também na quantidade de colágeno.

Outro trabalho conduzido por Liu et al. (2011), estudando a suplementação de dietas para frangos de corte com diferentes fontes de zinco, entre elas fontes orgânicas e inorgânicas também não observaram diferenças 
SCOTTÁ, B.A. et al. Influência dos minerais quelatados e inorgânicos no metabolismo, desempenho, qualidade da carcaça e da carne de frangos de corte. PUBVET, Londrina, V. 8, N. 9, Ed. 258, Art. 1710, Maio, 2014.

significativas nos parâmetros de carcaça avaliado, indicando não haver diferença entre a fonte orgânica ou inorgânica em relação às variáveis estudadas.

Outro mineral estudado para as características de qualidade de carcaça é o selênio. Sevcikova et al. (2006) estudaram a influencia de fontes orgânicas e inorgânicas de selênio sobre o rendimento de carcaça e a deposição de gordura abdominal e não observaram diferenças significativas para os parâmetros avaliados, mesmo tendo encontrado diferenças significativas no desempenho dos animais, sendo a fonte orgânica a que apresentou melhores resultados, indicando que mesmo para animais com melhor desempenho a qualidade da carcaça não é alterada, pois não ouve alteração na deposição de gordura abdominal, mostrando o benefício da fonte orgânica em detrimento á inorgânica.

\section{7 - Qualidade da Carne}

A qualidade da carne de frangos de corte é de grande importância para a indústria, pois esta relacionada á aceitabilidade do produto pelos consumidores. Características como cor, sabor, perda de água, $\mathrm{pH}$, força de cisalhamento, tempo de prateleira entre outras são as mais importantes.

Vários fatores podem afetar a qualidade da carne, como a genética, idade, sexo, manejo pré o pós abate e a nutrição, relacionado a esse ultimo fator, os minerais merecem destaque, pois suas funções no organismo podem alterar as características da carne o que pode levar a uma melhora do produto final. Os minerais quelatados têm sido utilizados na nutrição visando alem de um melhor desempenho e menor excreção de poluentes, alterar as características da carne, melhorando assim a qualidade do produto final.

Um dos minerais mais importantes quando se trata de qualidade da carne é o selênio. Este é um importante componente das selenoproteínas, sendo a principal a glutationa peroxidase do citosol, esta enzima atua sobre os peróxidos lipídicos e peróxidos de hidrogênio, convertendo-os em hidroxiácidos 
SCOTTÁ, B.A. et al. Influência dos minerais quelatados e inorgânicos no metabolismo, desempenho, qualidade da carcaça e da carne de frangos de corte. PUBVET, Londrina, V. 8, N. 9, Ed. 258, Art. 1710, Maio, 2014.

e água, respectivamente, durante essa reação duas moléculas de glutationa reduzida são convertidas em glutationa oxidadas, assim a maior concentração de selênio nas células, tornas estas menos susceptíveis ao processo oxidativo causado pelos radicais livres (Kohrle et al., 2000).

Alguns trabalhos têm demonstrado que a utilização de fontes orgânicas de selênio levam a um aumento deste mineral na carne o que diminui seu processo oxidativo. Bou et al. (2005) avaliaram a possível influencia da concentração de selênio sobre a oxidação lipídica da carne armazenada sob congelamento. A concentração de selênio na carne foi afetada pelas suplementações com selênio, sendo que somente a fonte orgânica provocou aumento significativo desse mineral quando comparado com a dieta sem suplementação, mas nenhum dos fatores estudados afetou a taxa de oxidação da carne armazenada.

O aumento do teor de selênio na carne também pode levar a uma menor perda de água da carne, pois como ele atua como antioxidante uma menor quantidade de células serão rompidas pelos radicais livres, diminuindo a quantidade de água liberada. Downs et al. (2000) encontaram baixa perda de água no gotejamento em files de peito de frangos alimentados com selenio quelatado ou sem suplementação de selenio, em comparação à suplementação com a fonte inorgânica. Uma fonte mais prontamente disponível de selenio (por exemplo, selenio orgânico) pode maximizar a atividade da enzima glutationa peroxidase, reduzindo assim o peróxido livre, e com isso uma menor destruição das células o que diminui a perda dos fluidos celulares e junto com eles água.

Boiago (2006) utilizou diferentes concentrações $(0,3$ ou $0,5 \mathrm{mg} / \mathrm{kg}$ ) e fontes (orgânica e inorgânica) de selênio na alimentação de frangos de corte e encontrou maior deposição do mesmo na carne do peito das aves quando se utilizou a fonte orgânica, independente da concentração utilizada, e também encontrou menor oxidação lipídica após armazenamento da carne por 15 dias e atribuiu isso ao maior teor de selênio na carne. Nesse mesmo trabalho foram encontradas diferenças significativas para o valor de luminosidade da carne 
SCOTTÁ, B.A. et al. Influência dos minerais quelatados e inorgânicos no metabolismo, desempenho, qualidade da carcaça e da carne de frangos de corte. PUBVET, Londrina, V. 8, N. 9, Ed. 258, Art. 1710, Maio, 2014.

sendo maior quando a fonte inorgânica foi utilizada, esse maior teor de luminosidade para a fonte inorgânica foi atribuído à relação existente entre luminosidade e capacidade de retenção de água do músculo, pois a fonte inorgânica proporcionou maiores perdas de água em decorrência da menor concentração do selênio na carne e, em consequência disso, maior luminosidade da carne.

Boiago (2010) avaliou a influencia de fontes orgânicas e inorgânicas de selênio, manganês e zinco em relação aos parâmetros de qualidade da carne e observou diferença significativa para a força de cisalhamento sendo esta menor para a fonte orgânica em comparação à fonte inorgânica, indicando que o uso desses minerais na forma orgânica pode levar a uma melhora na maciez da carne. Ele também observou um aumento significativo para a concentração de selênio e manganês na carne quando a fonte orgânica foi utilizada, o que não foi observado para o zinco.

Para a oxidação lipídica o mesmo autor não encontrou diferença significativa entre as duas fontes, mas observou interação entre a oxidação lipídica e a temperatura de criação sendo que a fonte orgânica na termoneutralidade levou a maior oxidação lipídica, em baixas temperaturas levou a menor oxidação e em temperaturas elevadas não se observou efeito algum. Isso pode levantar novas hipóteses, pois, segundo Choct \& Naylor (2004) o selênio possui poder antioxidante, sendo esse potencializado quando na forma orgânica, devido à sua maior biodisponibilidade.

O mesmo autor acima também avaliou a influencia das fontes orgânicas ou inorgânicas dos três minerais sobre as características de cor da carne, e não observou diferença significativa sobre os parâmetros de luminosidade (L) e teor de amarelo ( $\left.b^{*}\right)$, mas encontrou um aumento significativo do teor de vermelho ( $\left.a^{*}\right)$ quando as aves receberam a fonte inorgânica.

Outros minerais orgânicos como o manganês e o zinco também têm sido estudados visando avaliar a qualidade da carne de frangos de corte. Lu et al. (2006) estudou a influencia de fontes orgânicas e inorgânicas de manganês sobre os parâmetros de qualidade de carne, e não encontrou diferença 
SCOTTÁ, B.A. et al. Influência dos minerais quelatados e inorgânicos no metabolismo, desempenho, qualidade da carcaça e da carne de frangos de corte. PUBVET, Londrina, V. 8, N. 9, Ed. 258, Art. 1710, Maio, 2014.

significativa para as várias variáveis analisadas. Liu et al. (2011) estudou o efeito das fontes de zinco orgânico e inorgânico sobre os parâmetros de qualidade de carne e não observou diferença significativa para os parâmetros avaliados.

\section{8 - Conclusão}

Os minerais quelatados por apresentarem uma maior disponibilidade são mais prontamente absorvidos pelos animais, o que diminui a excreção destes, diminuindo a poluição ambiental. Eles também podem levar a melhoras no desempenho e nas características de carcaça e de carne.

\section{9 - Referências Bibliográficas}

ASSOCIATION OF AMERICAN FEED CONTROL OFFICIALS. Official Publication, p. 143. Association of American Feed Control Officials, 1999.

AO, T., PIERCE, J.L., POWER, R. et al Effects of feeding different forms of zinc and copper on the performance and tissue mineral content of chicks. Poultry Science. v. 88, p. 2171-2175, 2009.

BANKS, K.M., THOMPSON, K.L., RUSH, J.K. et al. Effects of Copper Source on Phosphorus Retention in Broiler Chicks and Laying Hens. Poultry Science. V. 83, p. 990-996, 2004.

BOIAGO, M. M. Características produtivas e qualitativas da carne de frangos alimentados com diferentes concentrações e fontes de selênio. 2006. 60 f. Dissertação (Mestrado em Zootecnia) - Universidade Estadual Paulista, Faculdade de Ciências Agrárias e veterinárias, Jaboticabal, 2006.

BOIAGO, M. M. Microminerais complexados a moléculas orgânicas sobre aspectos produtivos e qualitativos da carne de frangos de corte criados sob condições de estresse térmico. 2010. 85 f. Tese (Doutorado em Zootecnia) - Universidade Estadual Paulista, Faculdade de Ciências Agrárias e veterinárias, Jaboticabal, 2010.

BOU, R. et al. Effect of dietary fat source and $\mathrm{Zn}$ and Se supplements on the composition and consumer acceptability of chicken meat. Poultry Science, v. 84, n. 7, p.1129-1440, 2005.

CHOCT, M.; NAYLOR, J. The effect of dietary Se source and vitamin E levels on performance of male broilers. Asian-Australian Journal of Poutry Science, v. 17, n. 7, p. 1000-1006, 2004.

CHOWDHURY, S.D., PAIK, I.K., NAMKUNG, H. et al. Responses of broiler chickens to organic copper fed in the form of copper-methionine chelate. Animal Feed Science and Technolog, v. 115, p. 281-293, 2004.

DIECK, H.T., DORING, F., ROTH, H.P. et al. Changes in rat hepatic gene expression in response to zinc deficiency as assessed by DNA arrays. J. Nutr. v. 133, p. 1004-1010, 2003. 
DOWNS, K. M.; HESS, J. B.; BILGILI, S. F. Selenium source effect on broiler carcass characteristics, meat quality and drip loss. Journal of Applied Animal Research. Auburn, v.18, n. 1, p. 61-72, 2000.

HUANG, Y.L., LU, L., LI, S.F. et al. Relative bioavailabilities of organic zinc sources with different chelation strengths for broilers fed a conventional corn-soybean meal diet. J. Anim. Sci. v. 87, p. 2038-2046, 2009.

Ji, F., X. G. Luo, L. Lu, B. Liu, and S. X. Yu. Effect of manganese source on manganese absorption by the intestine of broilers. Poult. Sci. 85:1947-1952, 2006.

KESSLER, A.M.; SNIZEK JUNIOR, P.N.; BRUGALLI,I. Manipulação da Quantidade de Gordura na Carcaça de Frangos. In: Conferência Apinco 2000 de Ciência e Tecnologia Avícolas, 23 a 25 de maio, 2000. Campinas. Anais, v. 2. São Paulo: FACTA, 2000. p. 107-133.

KOHRLE, J. et al. Selenium in biology: facts and medical perspectives. Biology Chemistry. $v$. 381 , p. 849-864, 2000.

LIU, Z.H.; LU, L.; LI, S.F. et al. Effects of supplementation zinc source and level on growth performance, carcass traits, and meat quality of broilers. Poultry science, v. 90, p. 17821790, 2011.

LU, L.; LUO, X.G.; JI, C. et al. Effect of manganese supplementation and source on carcass traits, meat quality, and lipid oxidation in broilers. J. Anim. Sci., v. 85, p. 812-822, 2006.

MA, W. Q., SUN, H., ZHOU Y. et al Effects of Iron Glycine Chelate on Growth, Tissue Mineral Concentrations, Fecal Mineral Excretion, and Liver Antioxidant Enzyme Activities in Broilers, Biol Trace Elem. 2012.

NATIONAL RESEARCH COUNCIL - NRC, Nutrient requirements of poutry. National Academic Press, Washington, D.C., 1994.

MILES, R. D., \& HENRY, E.P.R. Relative trace mineral bioavailability. Ciência Animal Brasileira, v. 1, n. 2, p. 73-93, 2000.

PAIK, I.K., SEO, S.H., UM, J.S. et al. Effects of supplementary copper-chelate on the performance and cholesterol level in plasma and breast muscle of broiler chickens. Asian-Aus. J. Anim. Sci. v. 12, p. 794-798, 1999.

PAYNE, R.L., \& SOUTHERN, L.L. Comparison of Inorganic and Organic Selenium Sources for Broilers. Poultry Science. v. 84, p. 898-902, 2005.

ROSA, P. S. et al. Performance and carcass characteristics of broiler chickens with different growth potential and submitted to heat stress. Brazilian Journal of Poultry Science, Campinas, v. 9, p. 181-186, 2000.

ROSSI, P. et al. Influence of graded levels of organic Zinc (Bioplex $\mathrm{Zn}$ ) on growth performance and carcass traits of broilers fed diets cantaining organic selenium (Selplex). In: Annual Symposium Alltech of Biotechnology in the Feed and Food Industries, 20, 2007, Kentucky.

RUTZ, F., \& MURPHY, R. Minerais orgânicos para aves e suínos, I congresso internacional sobre uso da levedura na alimentação animal, cbna, campinas, 2009.

SEVCIKOVAL, S.; SKRIVANL, M.; DLOUHAL, M. et al. The effect of selenium source on the performance and meat quality of broiler chickens. Czech. J. Anim. Sci., v. 51, n. 10, p. 449$457,2006$.

TUCKER, L. Trace minerals in poutry nutrition-3 Redefining mineral nutrition- What we've learned so far. World Poultry. v. 24, n. 4, p. 18-19, 2008. 
VIEIRA, S.L. Considerações Sobre as Características de Qualidade de Carne de Frango e Fatores que Podem Afetá-la. In: Reunião Anual da Sociedade Brasileira de Zootecnia, 36, 1999, Porto Alegre. Anais. Porto Alegre: SBZ, 1999. 9 p.

YOON, I., WERNER, T.M., BUTLER, J.M. Effect of Source and Concentration of Selenium on Growth Performance and Selenium Retention in Broiler Chickens. Poultry Science. v. 86, p. 727-730. 2007. 